\title{
Sparing the contralateral submandibular gland without compromising PTV coverage by using volumetric modulated arc therapy
}

\author{
Patricia Doornaert ${ }^{*}$, Wilko FAR Verbakel, Derek HF Rietveld, Ben J Slotman and Suresh Senan
}

\begin{abstract}
Background: Salivary gland function decreases after radiation doses of 39 Gy or higher. Currently, submandibular glands are not routinely spared. We implemented a technique for sparing contralateral submandibular glands (CLSM) during contralateral elective neck irradiation without compromising PTV coverage.

Methods: Volumetric modulated arc therapy (RapidArc ${ }^{\mathrm{TM}}$ ) plans were applied in 31 patients with stage II-IV HNC without contralateral neck metastases, all of whom received elective treatment to contralateral nodal levels II-IV. Group 1 consisted of 21 patients undergoing concurrent chemo-radiotherapy, with elective nodal doses of 57.75 Gy (PTV elect) and 70 Gy to tumor and pathological nodes (PTV boost) in 7 weeks. Group 2 consisted of 10 patients treated with radiotherapy to 54.45 Gy to PTV elect and 70 Gy to PTV boost in 6 weeks. All clinical plans spared the CLSM using individually adapted constraints. For each patient, a second plan was retrospectively generated without CLSM constraints ('non-sparing plan').
\end{abstract}

Results: PTV coverage was similar for both plans, with $98.7 \%$ of $\mathrm{PTV}_{\text {elect }}$ and $99.2 \%$ of $\mathrm{PTV}_{\text {boost }}$ receiving $\geq 95 \%$ of the prescription dose. The mean CLSM dose in group 1 was 33.2 Gy for clinical plans, versus 50.6 Gy in 'nonsparing plans' $(p<0.001)$. In group 2, mean CLSM dose was 34.4 Gy for clinical plans, and 46.8 Gy for non-sparing plans ( $p=0.002)$.

Conclusions: Elective radiotherapy to contralateral nodal levels II-IV using RapidArc consistently limited CLSM doses well below $39 \mathrm{~Gy}$, without compromising PTV-coverage. Future studies will reveal if this extent of dose reduction can reduce patient symptoms.

Keywords: submandibular gland sparing, volumetric modulated arc therapy, RapidArc, head and neck cancer, dose distribution, xerostomia

\section{Background}

Bilateral nodal irradiation is indicated in patients with head and neck cancer who present with either locally advanced disease, or a tumor located in the midline. Irradiation delivered using conventional, non-intensity modulated techniques in these patients generally leads to a high degree of xerostomia [1]. Xerostomia is a major cause of morbidity following radiotherapy in patients with head and neck cancer, and arises due to irradiation of both major and minor salivary glands [2]. It causes physical difficulties in swallowing and speaking,

\footnotetext{
* Correspondence: p.doornaert@vumc.nl

Department of Radiation Oncology, VU University Medical Center, PB 7057, 1007 MB Amsterdam, The Netherlands
}

altered taste, predisposes to early dental caries, and is considered by patients to be a major cause of reduced quality of life (QoL) [3].

The use of intensity-modulated radiotherapy (IMRT) has allowed for reduction of doses to the parotid glands (PG) without compromising tumor coverage, and many authors have reported a reduction in xerostomia [4-14]. Although nearly two thirds of the stimulated saliva is produced by the PG, submandibular (SM) glands are largely responsible for salivary output in unstimulated conditions [15]. Unlike the PG which produces mainly serous secretions, SM glands produce mixed serous and mucinous secretions, and the latter accounts for a patient's subjective sense of moisture. Approaches that 
reduce doses to at least one SM gland can reduce the incidence of xerostomia [16,17]. Furthermore, there seems to be a better correlation between the incidence of xerostomia and the mean dose to the PGs and SM glands taken together as one organ, than to the PGs alone [18].

The drawbacks of conventional IMRT delivery are well recognized, with longer delivery times decreasing patient throughput [19], and an increase in the volume of normal tissues receiving low doses of radiation. Volumetric modulated arc therapy called RapidArc ${ }^{\mathrm{TM}}$ was introduced into clinical care in 2008 [20-23], and it uses continuous changes in the dose rate, the shape of the beam, and speed of gantry rotation to permit faster delivery of highly modulated IMRT plans [24]. Consequently, we implemented treatment plans that specifically spared both the PG and the contralateral submandibular gland (CLSM) in patients without contralateral (CL) neck metastases requiring bilateral neck irradiation. The present report describes the planning and clinical characteristics of $31 \mathrm{HNC}$ patients treated in this manner, all of whom also had comparative plans without CLSM.

\section{Methods}

\section{Patient selection}

Use of RapidArc at our department commenced in 2008, and we developed a constraint set aiming to spare the CLSM gland in 2009. The present study reports on the first 31 patients who were treated with clinical sparing of the CLSM gland. All patients had stage II-IV HNC without CL lymph node metastases (except for 1 patient who had one level IV positive node) and received elective treatment to CL nodal levels II-IV (Table 1).

Group 1 consisted of 21 patients who underwent concurrent chemoradiotherapy, including 14 patients with oropharyngeal cancer, 4 larynx cancer and 3 hypopharynx cancer. The majority $(\mathrm{n}=14)$ received three cycles of concurrent single-agent cisplatin $100 \mathrm{mg} / \mathrm{m} 2$. Three patients received induction chemotherapy (taxotere- cisplatin -5-FU) followed by weekly cis- or carboplatin, 2 patients received cisplatinum $40 \mathrm{mg} / \mathrm{m} 2$ weekly, and 2 patients were only fit to receive concurrent radiotherapy with cetuximab. Group 2 consisted of 10 patients who were treated using only accelerated radiotherapy (6 fractions/week), and included oropharynx $(\mathrm{n}=6)$, larynx $(\mathrm{n}$ $=3)$ and hypopharynx $(\mathrm{n}=1)$ cancer.

All patients were positioned in a 5 point fixation mask (Posicast ${ }^{\circledR}$ Thermoplastics, Civco Medical Solutions). The gross tumor volume (GTV) was delineated on a contrast-enhanced planning CT scan acquired with 2.5$\mathrm{mm}$ slice thickness. Target volumes were defined by coregistration of diagnostic MRI scans and/or PET scans. The gross tumor volume (GTV) was defined as the primary tumor and involved lymph nodes on imaging and examination under anesthesia. The 'boost' clinical target volume $\left(\mathrm{CTV}_{\text {boost }}\right)$ comprised the GTV with a margin of $0.5 \mathrm{~cm}$, and was corrected for anatomical boundaries. The 'elective' CTV $\left(\mathrm{CTV}_{\text {elect }}\right)$ included the $\mathrm{CTV}_{\text {boost }}$ plus $0.5 \mathrm{~cm}$ and bilateral elective lymph nodes: CL levels II-IV and at least IL levels II-V, and level I, VI and/or retropharyngeal nodes in accordance with published guidelines [25,26]. A margin of an additional 3 (upper part) to 5 (shoulder region) $\mathrm{mm}$ was taken to create planning target volumes (PTVs).

\section{Planning objectives and techniques}

The objectives used for the target volumes and organs at risk are summarized in Table 2. In group 1, dose prescription was set to $57.75 \mathrm{~Gy}$ at $1.65 \mathrm{~Gy} /$ fraction to the $\mathrm{PTV}_{\text {elect }}$ and $70 \mathrm{~Gy}$ at $2 \mathrm{~Gy} /$ fraction to the PTV $\mathrm{P}_{\text {boost }}$ delivered as a simultaneous integrated boost (SIB). In group 2, patients received 54.25 Gy at 1.55 Gy/fraction tot the PTV $\mathrm{Plect}_{\text {. }}$ A standard constraint set was used for RA optimization, aiming to achieve at least. $95 \%$ of the boost dose in $99 \%$ of the PTV boost and $95 \%$ of the elective dose in $98 \%$ of the $\mathrm{PTV}_{\text {elect }}$, while keeping the boost and elective volumes receiving $>107 \%$ of the prescribed dose as small as possible. This constraint set is similar to that described previously [24], except for the addition of objectives to spare the CLSM gland. The maximum dose specified for the spinal canal was 36-40 Gy. Priorities for the PTVs, spinal cord and salivary glands were 120-130, 125 and 80 respectively. Four dose objectives were set for both PGs and the CLSM gland, and only those objectives were interactively adapted for each individual patient during the first 2 to 3 levels of a 5-level multi-resolution optimization process that aimed to keep the mean CLSM dose low without compromising PTV coverage. The built-in normal tissue objective with a priority of 80 , and 3 constraints on a $1 \mathrm{~cm}$ thick ring created around the PTVs were used to enforce a steep dose fall-off outside the target volumes.

Optimization and dose calculations were performed using the Eclipse treatment planning system (version 8.2.23) in 10 patients, and subsequently Eclipse version 8.6.15 for 21 patients (Varian Medical Systems, Palo Alto). Treatment delivery was performed using $6 \mathrm{MV}$ photon beams from a Varian 2300 linac with the Millennium 120-MLC. The Anisotropic Analytical Algorithm (AAA) photon dose calculation algorithm was used with a calculation grid of $2.5 \mathrm{~mm}$. Each plan consisted of 2 coplanar arcs of $358^{\circ}$ (one counterclockwise (CCW), one clockwise $(\mathrm{CW}))$. In the first 10 patients, a sequential approach was used, in which the first arc plan was used as a base dose plan for the second arc plan which compensated for possible under- or overdosage in the first arc plan, leading to a homogeneous dose in the PTV 
Table 1 Patient characteristics

\begin{tabular}{|c|c|c|c|c|c|c|}
\hline Patient & Site & subsite & TNM & stage & elective dose (Gy) & chemotherapy \\
\hline 1 & oropharynx & tonsil & $\mathrm{T} 4 \mathrm{~N} 2 \mathrm{~b}$ & IV & 57.75 & TPF + carbo weekly \\
\hline 2 & oropharynx & base of tongue & T3NO & III & 57.75 & CDDP $3 x$ \\
\hline 3 & oropharynx & tonsil & T3NO & III & 57.75 & cetuximab \\
\hline 4 & oropharynx & tonsil & $\mathrm{T} 2 \mathrm{~N} 2 \mathrm{~b}$ & IV & 57.75 & CDDP weekly \\
\hline 5 & oropharynx & tonsil & T4bNO & IV & 57.75 & TPF + CDDP weekly \\
\hline 6 & oropharynx & base of tongue & $\mathrm{T} 3 \mathrm{~N} 2 \mathrm{~b}$ & IV & 57.75 & CDDP $3 x$ \\
\hline 7 & oropharynx & tonsil & T3N1 & III & 57.75 & CDDP $3 x$ \\
\hline 8 & oropharynx & tonsil & $\mathrm{T} 2 \mathrm{~N} 2 \mathrm{~b}$ & IV & 57.75 & CDDP $3 x$ \\
\hline 9 & oropharynx & pharyngeal wall & $\mathrm{T} 3 \mathrm{~N} 2 \mathrm{~b}$ & IV & 57.75 & CDDP $3 x$ \\
\hline 10 & oropharynx & tonsil & $\mathrm{T} 3 \mathrm{~N} 2 \mathrm{~b}$ & IV & 57.75 & CDDP $3 x$ \\
\hline 11 & oropharynx & tonsil & $\mathrm{T} 2 \mathrm{~N} 2 \mathrm{~b}$ & IV & 57.75 & CDDP $3 x$ \\
\hline 12 & oropharynx & base of tongue & T2N1 & III & 57.75 & CDDP $3 x$ \\
\hline 13 & oropharynx & tonsil & T4N1 & IV & 57.75 & TPF + carbo weekly \\
\hline 14 & oropharynx & base of tongue & T3NO & III & 57.75 & cetuximab \\
\hline 15 & larynx & supraglottis & T3N1 & III & 57.75 & CDDP weekly \\
\hline 16 & larynx & supraglottis & T3NO & III & 57.75 & CDDP $3 x$ \\
\hline 17 & larynx & supraglottis & T4NO & IV & 57.75 & CDDP $3 x$ \\
\hline 18 & larynx & supraglottis & T3NO & III & 57.75 & CDDP $3 x$ \\
\hline 19 & hypopharynx & postcricoid & $\mathrm{T} 3 \mathrm{~N} 2 \mathrm{C}$ & IV & 57.75 & CDDP $3 x$ \\
\hline 20 & hypopharynx & piriform sinus & $\mathrm{T} 4 \mathrm{aN} 2 \mathrm{~b}$ & IV & 57.75 & CDDP $3 x$ \\
\hline 21 & hypopharynx & piriform sinus & $\mathrm{T} 4 \mathrm{~N} 2 \mathrm{~b}$ & IV & 57.75 & CDDP $3 x$ \\
\hline 22 & oropharynx & tonsil & T2NO & $\|$ & 54.25 & \\
\hline 23 & oropharynx & base of tongue & T1N1 & III & 54.25 & \\
\hline 24 & oropharynx & tonsil & T2NO & $\|$ & 54.25 & \\
\hline 25 & oropharynx & base of tongue & T3NO & III & 54.25 & \\
\hline 26 & oropharynx & soft palate & T2N1 & III & 54.25 & \\
\hline 27 & oropharynx & soft palate & T1NO & 1 & 54.25 & \\
\hline 28 & larynx & transglottis & $\mathrm{T} 2 \mathrm{~N} 2 \mathrm{~b}$ & IV & 54.25 & \\
\hline 29 & larynx & glottis & T3NO & III & 54.25 & \\
\hline 30 & larynx & supraglottis & T2NO & $\|$ & 54.25 & \\
\hline 31 & hypofarynx & piriform sinus & T2N1 & III & 54.25 & \\
\hline
\end{tabular}

CDDP: cisplatinum

CDDP 3x: 3 cycles of cisplatinum $100 \mathrm{mg} / \mathrm{m}^{2}$

TPF: docetaxel $75 \mathrm{mg} / \mathrm{m}^{2}$ day 1 , cisplatinum $75 \mathrm{mg} / \mathrm{m}^{2}$ day $1,5-\mathrm{FU} 750 \mathrm{mg} / \mathrm{m}^{2}$ day $1-5$

[23]. In the last 21 patients, the 2 arcs were simultaneously optimized. To appreciate the target coverage in the areas where the PTV approaches the surface, a local build-up of $6 \mathrm{~mm}$ (to overcome dose build-up under the skin) was used for optimization purposes.

Table 2 Planning objectives/constraint set

\begin{tabular}{lrrr}
\hline Target Volume & min dose (Gy) & max dose (Gy) & priority \\
\hline PTV elective (1.65 Gy/fr) & 57 & 58.5 & $120-130$ \\
PTV elective (1.55 Gy/fr) & 53.5 & 55 & $120-130$ \\
PTV boost & 69 & 71 & $120-130$ \\
spinal cord & & 36 & 125 \\
standard ring & $\mathrm{DVH}$ & $90-110$ \\
parotids & $\mathrm{DVH}$, adapt during first iterations & 80 \\
CLSM & $\mathrm{DVH}$, adapt during first iterations & 80 \\
Shoulders & & 20 & 75 \\
\hline
\end{tabular}

For plan evaluation, the boost and elective volumes receiving at least $95 \%$ of the prescribed doses (V95), as well as the V107, were registered. This was done in the plans using the local build-up for optimisation purposes. A conformity index (CI), which was defined as the ratio between the volume receiving at least $95 \%$ of the prescribed boost dose and the volume of the PTV boost, was calculated. The mean doses of both PGs, the CLSM gland and the maximum dose to the spinal canal were also registered.

In order to confirm the results achieved in our initial 31 patients, the CLSM doses of 25 consecutive patients treated subsequently using the same technique, were also analyzed. All patients had stage II-IV disease, were treated electively to the CL levels II-IV and received a dose of 70 Gy to the PTV $\mathrm{Poost}_{\text {bo }}$ and 54.25 Gy to the PTV $\mathrm{elect}_{\text {. }}$ 


\section{Planning study}

For purposes of the present analysis, a second plan was retrospectively generated using identical constraints on all volumes except the CLSM gland (referred to as the 'non-sparing plan'). Doses to the PTVs, PGs, CLSM gland and spinal canal were registered and compared for both plans. Volumes encompassed by the $95 \%$ isodose line (V95) of the elective and boost dose were generated for the sparing and non-sparing plans and compared by using the Wilcoxon signed-ranks test. $\mathrm{P}<$ 0.05 was considered as significant.

\section{Quality assurance (QA)}

Individual plan QA was performed for all patients. For 10 patients, dose distributions were measured using Gafchromic ${ }^{\circledR}$ EBT films inserted in 1-3 coronal planes of a cube polystyrene phantom, allowing dose verification during a single treatment session [23]. In the remaining 21 patients, QA was performed using the MatriXx ionization chamber array (IBA, Louvain-la-Neuve, Belgium) in one coronal plane of an in-house designed polystyrene phantom. The coronal planes were selected to measure a combination of boost and elective doses. All measurements were performed for the combination of the two arcs and they were compared to the calculated dose of the same patient plan on the CT-scan with the respective phantom. A gamma-evaluation was performed, using dose differences of $3 \%$ and distance to agreement of $2 \mathrm{~mm}$.

Routine patient set-up was performed using two orthogonal kV-images (OBI, Varian Medical Systems) performed prior to each of the first 3 fractions, which were registered to digitally computed radiographs from the planning CT-scan using translations only. After the fourth fraction, patients were positioned according to the mean of the first 3 set-ups. The set-up procedure was repeated after 20 fractions, and a cone beam CTscan $(\mathrm{CBCT})$ was then performed to ensure PTV coverage.

\section{Toxicity and quality of life assessment}

Patients are all included in a standardized follow-up program with weekly evaluation by the radiation oncologist and scoring of toxicity according to the RTOG Radiation Morbidity Scoring Criteria [27]. Health-related QoL was routinely assessed using the EORTC QLQ-C30 and $H \& N 35$ questionnaires at baseline, 1 and 6 months post treatment and at 6 -month intervals thereafter $[28,29]$.

\section{Results}

All 31 patients completed CLSM sparing radiotherapy as was planned. Median follow up was 19 months (range 14-25 months). To date, no regional recurrences have been observed. Two patients developed a local recurrence and underwent a total laryngectomy. Two patients had a local recurrence with lung metastases. One patient developed lung metastases only.

\section{Target coverage}

The mean volumes of PTV elect and PTV boost $\left(588 \mathrm{~cm}^{3}\right.$ and $178 \mathrm{~cm}^{3}$, respectively) for patients in group 1 were similar to that in group $2\left(565 \mathrm{~cm}^{3}\right.$ and $\left.118 \mathrm{~cm}^{3}\right)$. Mean PTV coverage, CI and OAR doses for both the sparing and the non-sparing plans, are summarised in Table 3. The PTV coverage of all 31 patients studied was excellent, with on average $98.7 \%$ of $\mathrm{PTV}_{\text {elect }}$ and $99.2 \%$ of $\mathrm{PTV}_{\text {boost }}$ receiving $\geq 95 \%$ of the prescription dose. In 'non-sparing' plans, the corresponding PTV coverage was $98.9 \%$ and $99.2 \%$, respectively. For both plans, on average, only $0.8 \%$ of $\mathrm{PTV}_{\text {boost }}$ received $>107 \%$. The resulting plan $\mathrm{CI}$ was 1.18 in group 1 , and 1.14 in group 2 (not different from the CI 'non-sparing' plans).

Sparing of the CLSM gland did not significantly reduce the volume encompassed by the $95 \%$ isodoseline of the elective or boost doses compared to the non-sparing plans (Wilcoxon signed-ranks test $\mathrm{p}=0.16$ and $\mathrm{p}=0.64$ respectively). An example of the clinical and non-sparing plan in a typical patient can be appreciated in Figure 1.

\section{Organs at risk (OAR)}

With the exception of the mean dose in the CLSM gland, no differences in doses to other OARs were observed for clinical and non-sparing plans. In group 1, the mean CLSM gland dose was 33.2 Gy (clinical plans) and 50.6 Gy (non-sparing) ( $\mathrm{p}<0.001$ ). The maximum dose to the spinal canal was on average 40.2 Gy (compared to 40 Gy in the non-sparing plans). IL and CL parotids received 32.1 Gy and 21.9 Gy respectively (versus 31.5 Gy and $21.5 \mathrm{~Gy}$ in the non-sparing plans).

In group 2, the mean CLSM gland dose was 34.4 Gy for clinical plans, and 46.8 Gy for non-sparing plans ( $\mathrm{p}$ 0.002). The maximum dose to the spinal canal was 38.6 Gy (as opposed to 38.3 Gy in the non-sparing plans). Clinical IL and CL parotid doses were 25.7 Gy and 19.6 Gy respectively, versus $25.8 \mathrm{~Gy}$ and $19.6 \mathrm{~Gy}$ in nonsparing plans.

In the follow up cohort of 25 patients treated using the same technique, the mean CLSM dose was $32.8 \mathrm{~Gy}$. Both $\mathrm{PTV}_{\text {elect }}$ and $\mathrm{PTV}_{\text {boost }}$ coverage was again excellent, with $98.4 \%$ and $99.3 \%$ of volumes receiving $95 \%$ of the prescription dose.

\section{Acute toxicity}

Acute toxicity observed was consistent with the toxicity seen in patients treated with conventional IMRT delivery to these doses [6]. In group 1 (21 patients), 5 patients experienced RTOG grade 3 cutaneous toxicity 
Table 3 Results

\begin{tabular}{llllllllllll}
\hline Site & & SM CL & $\begin{array}{l}\text { SM CL } \\
\text { (non- } \\
\text { sparing) }\end{array}$ & & PG IL & $\begin{array}{l}\text { PG IL } \\
\text { (non- } \\
\text { sparing) }\end{array}$ & PG CL & $\begin{array}{l}\text { PG CL } \\
\text { (non- } \\
\text { sparing) }\end{array}$ & Sp C & $\begin{array}{l}\text { Sp C } \\
\text { (non- } \\
\text { sparing) }\end{array}$ & V B $\geq 95 \%$ V E $\geq 95 \%$ \\
\hline A & mean & 33.7 & 51.5 & 34.2 & 33.3 & 21.8 & 21.4 & 42.1 & 41.9 & 99.3 & 98.9 \\
& range & $(46.5-57.3)$ & $(24.7-41.6)$ & $(16.6-54.3)$ & $(16.3-53.2)$ & $(12.2-31.8)$ & $14.2-32.1)$ & $(37-50)$ & $(35.8-49)$ & $(98.9-99.9)$ & $(98.2-99.5)$ \\
B & mean & 32.4 & 49 & 27.9 & 27.8 & 22 & 21.9 & 36.4 & 36.3 & 99.7 & 98.5 \\
& range & $(44.3-52.8)$ & $(29.7-39.5)$ & $(16.4-55.5)$ & $(16-55.7)$ & $(16.7-30.6)$ & $(16.7-30.3)$ & $(23-49.8)$ & $(23-49.8)$ & $(99-99.9)$ & $(97.9-98.9)$ \\
C & mean & 35.1 & 47.1 & 28.7 & 29.1 & 21.9 & 22 & 40 & 39.8 & $98.5^{*}$ & 98.9 \\
& range & $(43.7-52.4)$ & $(26.6-40.6)$ & $(16.5-48.2)$ & $(17-46.3)$ & $(13.6-30.9)$ & $(14.5-30.7)$ & $(30-44.9)$ & $(29.7-45.3)$ & $(96.2-99.6)$ & $(97.9-98.9)$ \\
D & mean & 33.4 & 46.4 & 21.2 & 21 & 16.2 & 16 & 36.4 & 36 & 99.6 & 98.3 \\
& range & $(42.2-51.8)$ & $(30-36.8)$ & $(12.7-35.7)$ & $(12.4-35.6)$ & $(10.7-26.1)$ & $(10.3-26.3)$ & $(24.7-41)$ & $(24.4-41.2)$ & $(99.1-99.9)$ & $(97.6-98.9)$ \\
\hline
\end{tabular}

A: oropharynx, elective dose 57.75 Gy (14 patients) Doses in Gy

B: larynx/hypopharynx, elective dose 57.75 Gy (7 patients) Sp C: spinal cord

C: oropharynx, elective dose 54.25 Gy (6 patients)

D: larynx/hypopharynx, elective dose 54.25 Gy (4 patients)

V B $\geq 95 \%$ :\% of PTV boost receiving $\geq 95 \%$ of the prescribed dose

V E $\geq 95 \%: \%$ of PTV elective receiving $\geq 95 \%$ of the prescribed dose

*: in 1 patient with $\mathrm{T} 1$ carcinoma of the soft palate, $96.2 \%$ of $\mathrm{PTV}_{\text {boost }}$ received $95 \%$ of prescribed dose, this was accepted because of the fact that a large part of the PTV boost consisted of air.

(moist desquamation). Half (10) of all patients had a confluent mucositis (RTOG grade 3 toxicity) and 19 patients required opioid analgesia. Fifteen patients developed grade 2 xerostomia with markedly altered taste.
Prophylactic placement of a percutaneous endoscopic gastrostomy tube (PEG-tube) was performed in 19 patients, and all but one patient actually used the PEGtube.

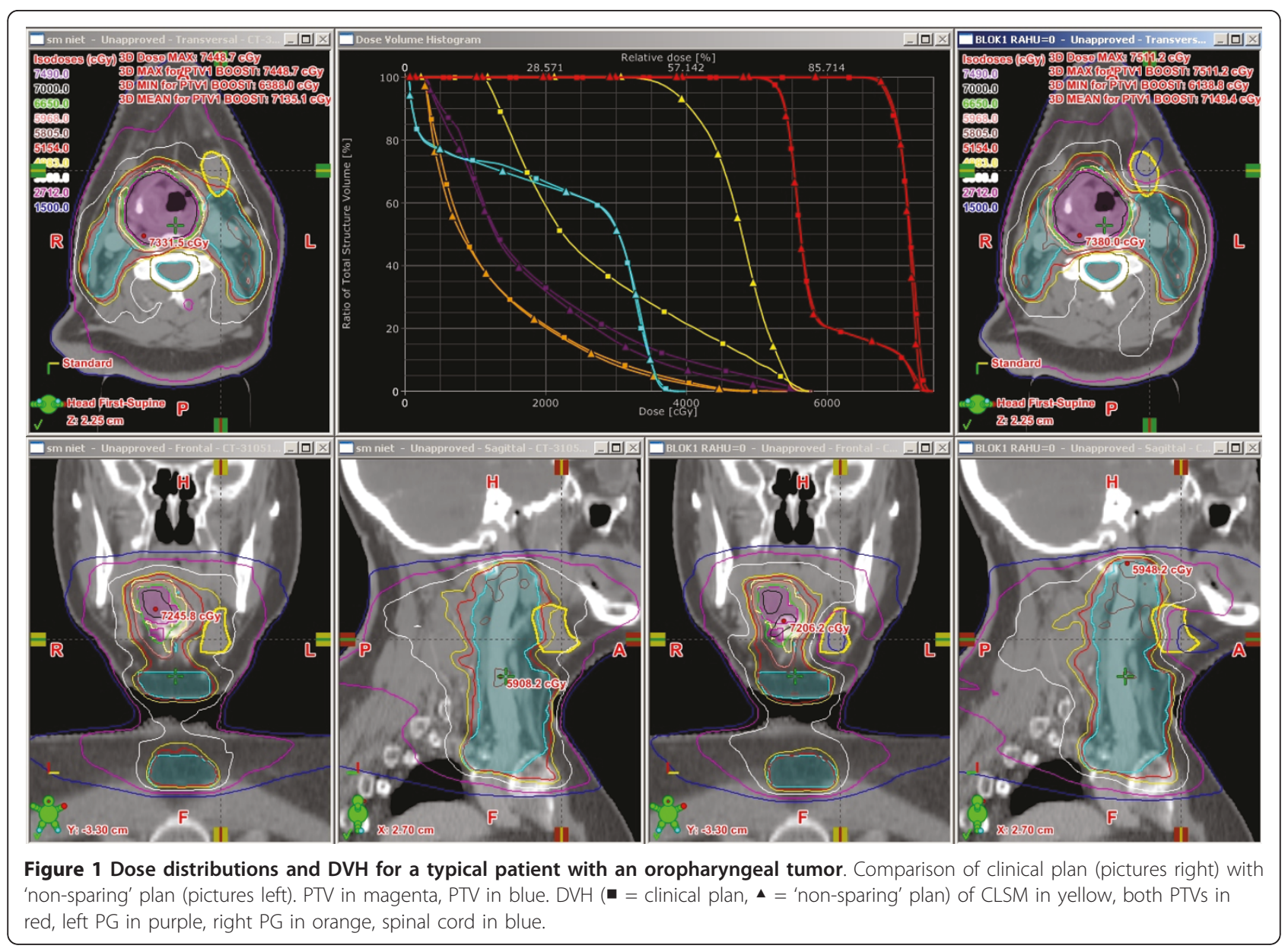


In group 2 (10 patients), 7 patients developed confluent mucositis, and 9 patients experienced a markedly altered taste our dry mouth (xerostomia grade 2). No preventive PEG tubes were placed. Only one patient needed a nasogastric tube. Eight patients required opioids.

\section{Quality assurance}

Film and MatriXx measurements showed that on average only $1.3 \%$ of the measurement points exceeded a combination of dose difference $>3 \%$ or distance to agreement $>2 \mathrm{~mm}$ (range $0-4.6 \%$ ). For only 6 of the patients, more than $3 \%$ of the measured points exceeded this limit.

\section{Discussion}

The pathogenesis of xerostomia is complex and appears to depend on not only PG function, as a discrepancy was noted between preserved PG function measured using objective tools, and subjective patient-reported xerostomia [30-33]. As particularly the mucinous secretions of the SM gland contribute to the subjective feeling of oral hydration, we developed and clinically implemented a technique to spare both the PGs and CLSM gland in patients undergoing elective irradiation to clinically negative CL level II-IV nodes. Our main findings are that reductions in mean dose to the CLSM gland to 33.2 Gy and 34.4 Gy, respectively, is possible in who need to undergo elective doses of 57.75 Gy and 54.25 Gy.

SM glands are located adjacent to the jugulodigastric nodes, which are the first echelon for most HNC tumors. Consequently, SM sparing is infrequently considered for fear of reducing PTV coverage [2]. We observed no compromise in PTV coverage in most patients, although 5 clinical plans had a minor underdosage (to $90 \%$ of the prescribed elective dose) in $0.5 \mathrm{~cm}^{3}$ to the $\mathrm{PTV}_{\text {elect }}$ in the vicinity of the CLSM. In all these 5 patients, the coverage of the PTV $\mathrm{Plect}_{\text {el }}$ met our clinical acceptance criteria as $97.9 \%-98.6 \%$ was covered by $95 \%$ of the elective dose. For the purposes of the current study, plans for all these 5 patients were repeated using a PTV elect $_{\text {margin of } 5}$ $\mathrm{mm}$ (3 $\mathrm{mm}$ standard $+2 \mathrm{~mm}$ extra) for the PTV regions directly adjacent to the CLSM gland. In all patients, the volume of underdosage could be reduced to $0-0.2 \mathrm{~cm}^{3}$. In 2 patients, the mean CLSM dose remained the same, in 2 patients there was an increase of 1.6 Gy and in 1 patient an increase from 31.8 to $35.7 \mathrm{~Gy}$. Consequently, we cur-

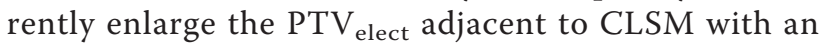
extra $2 \mathrm{~mm}$ in order to reduce the likelihood of creating a small rim of underdosage in the $\mathrm{PTV}_{\text {elect. }}$. It is reassuring to note the application of our technique in an additional 25 patients revealed that the reduction in CLSM doses was maintained.
With a short median follow up in our 31 patients of 19 months, no contralateral regional recurrences were observed. Recent work in 285 patients indicates that isolated regional relapse in the elective contralateral neck are very uncommon after the use of IMRT [34]. These authors delivered a dose of 56 Gy in 32 fractions to elective regions, which was comparable to the doses used in our patients. As we found no significant differences between the clinical and the non-sparing plans in PTV receiving at least $95 \%$ of the elective and boost doses, the likelihood of recurrences in the vicinity of the CLSM are expected to be low.

Few studies have addressed the dose-response relationships of the SM gland. A study measuring unstimulated whole mouth salivary flow suggested a $\mathrm{TD}_{50}$ of $32.6 \mathrm{~Gy}$ at 6 months and $34.1 \mathrm{~Gy}$ at 12 months for the SM gland [35]. A study in 148 patients treated with IMRT, where no attempt was made to spare the SM glands, resulted in only a limited number of data points in the low-dose region of the SM [36]. Data from this study suggested an exponential mean dose-related decrease in SM output, up to a threshold of $39 \mathrm{~Gy}$, above which little or no recovery of salivary flow was seen.

Other approaches for sparing the SM gland have been reported. A planning study in 10 patients with oropharyngeal cancer which delivered a dose of 54 Gy to the CL PTV $\mathrm{Plect}_{\text {, }}$, reported a reduction in mean CLSM gland dose from 54 Gy to 40 Gy [37] However, these authors had to accept an underdosage in the vicinity of the CL $\mathrm{PTV}_{\text {elect }}$ to $90 \%$ of the prescribed dose. Surgical transfer of the SM gland into the submental space outside the field can lead to a significant improvement of salivary function [16]. The same authors recently performed a planning study combining SM gland transfer with helical tomotherapy in patients undergoing postoperative RT, and reported achieving a mean dose of 23 Gy in the spared SM gland [38]. In a study where 18 patients actually underwent treatment using plans to limit mean CLSM gland dose to below 26 Gy, no clear definition of the doses in CTVs and PTVs was described [35]. In this study, an underdosage in PTV of up to $10 \%$ at the periphery of the CLSM gland was accepted and volumes of underdosage were not reported [39]. Another study recently reported on CLSM sparing in mostly postoperative patients, who comprised 47 of the 52 cases [17]. An impressive reduction in the mean dose to the CLSM gland from 57.4 Gy (non-spared group) to 20.4 Gy (spared group) was described. However, a coverage of 95\% of the PTV was considered acceptable and no data on regions of potential underdosage were described. The lower mean CLSM gland dose resulted into a lower RTOG xerostomia score and stimulatated slivary flow rates up to 6 months after therapy (but not thereafter). 
The authors reported that unstimulated salivary flow rates were significantly better at all time points.

A limitation of our study is the lack of objective assessment of the SM salivary flow, although it must be recognized that the assessment of xerostomia can be subjective and that objective salivary flow measurements may not translate into patient-reported complaints $[12,14,30,33]$. Since a mean dose of less than 35 Gy to the CLSM gland was achieved, we hope to demonstrate a significant further decrease in patient-scored xerostomia with longer follow-up.

\section{Conclusion}

In HNC patients with a clinically negative contralateral neck, requiring elective RT to the CL nodal levels II-IV, use of RapidArc significantly reduced mean doses to the CLSM gland to below $35 \mathrm{~Gy}$, without compromising PTV coverage. Longer follow-up is required to exclude the potential risk of tumor recurrences in the contralateral neck and to demonstrate a significant decrease in xerostomia.

\begin{abstract}
Authors' contributions
PD collected the clinical and treatment data, created the "non-sparing" plans, WFARV developed the constraint set, PD and SS drafted the manuscript. All authors contributed to the drafting of the manuscript and approved the final manuscript
\end{abstract}

\section{Competing interests}

The VU University Medical Center has a research collaboration with Varian Medical Systems (Palo Alto, CA).

Received: 15 February 2011 Accepted: 16 June 2011

Published: 16 June 2011

\section{References}

1. Bjordal K, Kaasa S, Mastekaasa A: Quality of life in patients treated for head and neck cancer: a follow-up study 7 to 11 years after radiotherapy. Int J Radiat Oncol Biol Phys 1994, 28:847-856.

2. Dirix P, Nuyts S: Evidence-based organ-sparing radiotherapy in head and neck cancer. Lancet Oncol 2010, 11:85-91.

3. Bjordal K, Kaasa S: Psychometric validation of the EORTC Core Quality of Life Questionnaire, 30-item version and a diagnosis-specific module for head and neck cancer patients. Acta Oncol 1992, 31:311-321.

4. Dijkema T, Terhaard CH, Roesink JM, Braam PM, van Gils CH, Moerland MA, Raaijmakers CP: Large cohort dose-volume response analysis of parotid gland function after radiotherapy: intensity-modulated versus conventional radiotherapy. Int J Radiat Oncol Biol Phys 2008, 72:1101-1109.

5. Braam PM, Terhaard CH, Roesink JM, Raaijmakers CP: Intensity-modulated radiotherapy significantly reduces xerostomia compared with conventional radiotherapy. Int J Radiat Oncol Biol Phys 2006, 66:975-980.

6. Vergeer MR, Doornaert PA, Rietveld DH, Leemans CR, Slotman BJ, Langendijk JA: Intensity-modulated radiotherapy reduces radiationinduced morbidity and improves health-related quality of life: results of a nonrandomized prospective study using a standardized follow-up program. Int J Radiat Oncol Biol Phys 2009, 74:1-8.

7. Roesink JM, Moerland MA, Battermann JJ, Hordijk GJ, Terhaard CH: Quantitative dose-volume response analysis of changes in parotid gland function after radiotherapy in the head-and-neck region. Int J Radiat Oncol Biol Phys 2001, 51:938-946.

8. Pow EH, Kwong DL, MCMillan AS, Wong MC, Sham JS, Leung LH, Leung WK: Xerostomia and quality of life after intensity-modulated radiotherapy vs. conventional radiotherapy for early-stage nasopharyngeal carcinoma: initial report on a randomized controlled clinical trial. Int J Radiat Oncol Biol Phys 2006, 66:981-991.

9. Nutting C, A'Hern R, Rogers MS, Sydenham MA, Adab F, Harrington K, Jefferies $S$, Scrase C, Yap BK, Hall E: First results of a phase III multicenter randomized controlled trial of intensity modulated (IMRT) versus conventional radiotherapy (RT) in head and neck cancer (PARSPORT: ISRCTN48243537; CRUK/03/005). J Clin Oncol (Meeting Abstracts) 2009, 27 LBA6006.

10. Lee NY, O'Meara W, Chan K, la-Bianca C, Mechalakos JG, Zhung J, Wolden SL, Narayana A, Kraus D, Shah JP, Pfister DG: Concurrent chemotherapy and intensity-modulated radiotherapy for locoregionally advanced laryngeal and hypopharyngeal cancers. Int J Radiat Oncol Biol Phys 2007, 69:459-468.

11. Huang K, Xia P, Chuang C, Weinberg V, Glastonbury CM, Eisele DW, Lee NY, Yom SS, Phillips TL, Quivey JM: Intensity-modulated chemoradiation for treatment of stage III and IV oropharyngeal carcinoma: the University of California-San Francisco experience. Cancer 2008, 113:497-507.

12. Eisbruch A, Ship JA, Martel MK, Ten Haken RK, Marsh LH, Wolf GT, Esclamado RM, Bradford CR, Terrell JE, Gebarski SS, Lichter AS: Parotid gland sparing in patients undergoing bilateral head and neck irradiation: techniques and early results. Int J Radiat Oncol Biol Phys 1996, 36:469-480.

13. Eisbruch A, Ship JA, Dawson LA, Kim HM, Bradford CR, Terrell JE, Chepeha DB, Teknos TN, Hogikyan ND, Anzai Y, Marsh LH, Ten halen RK, Wolf GT: Salivary gland sparing and improved target irradiation by conformal and intensity modulated irradiation of head and neck cancer. World J Surg 2003, 27:832-837.

14. Chao KS, Deasy JO, Markman J, Haynie J, Perez CA, Purdy JA, Low DA: A prospective study of salivary function sparing in patients with head-andneck cancers receiving intensity-modulated or three-dimensional radiation therapy: initial results. Int J Radiat Oncol Biol Phys 2001, 49:907-916.

15. Edgar WM: Saliva and dental health. Clinical implications of saliva: report of a consensus meeting. Br Dent J 1990, 169:96-98.

16. Jha N, Seikaly H, Harris J, Williams D, Liu R, McGaw T, Hofmann H, Robinson D, Hanson J, Barnaby P: Prevention of radiation induced xerostomia by surgical transfer of submandibular salivary gland into the submental space. Radiother Oncol 2003, 66:283-289.

17. Wang ZH, Yan C, Zhang ZY, Zhang CP, Hu HS, Tu WY, Kirwan J, Mendenhall WM: Impact of Salivary Gland Dosimetry on Post-IMRT Recovery of Saliva Output and Xerostomia Grade for Head-and-Neck Cancer Patients Treated with or without Contralateral Submandibular Gland Sparing: A Longitudinal Study. Int J Radiat Oncol Biol Phys 2010.

18. Strigari L, Benassi M, Arcangeli G, Bruzzaniti V, Giovinazzo G, Marucci L: A novel dose constraint to reduce xerostomia in head-and-neck cancer patients treated with intensity-modulated radiotherapy. Int J Radiat Oncol Biol Phys 2010, 77:269-276.

19. Palma DA, Verbakel WF, Otto K, Senan S: New developments in arc radiation therapy: a review. Cancer Treat Rev 2010, 36:393-399.

20. Kjaer-Kristoffersen F, Ohlhues L, Medin J, Korreman S: RapidArc volumetric modulated therapy planning for prostate cancer patients. Acta Oncol 2009, 48:227-232.

21. Lagerwaard FJ, Meijer OW, van der Hoorn EA, Verbakel WF, Slotman BJ, Senan S: Volumetric modulated arc radiotherapy for vestibular schwannomas. Int J Radiat Oncol Biol Phys 2009, 74:610-615.

22. Vanetti E, Clivio A, Nicolini G, Fogliata A, Ghosh-Laskar S, Agarwal JP, Upreti RR, Budrukkar A, Murthy V, Deshpande DD, Shrivastava SK, Dinshaw KA, Cozzi L: Volumetric modulated arc radiotherapy for carcinomas of the oro-pharynx, hypo-pharynx and larynx: a treatment planning comparison with fixed field IMRT. Radiother Oncol 2009, 92:111-117.

23. Verbakel WF, Cuijpers JP, Hoffmans D, Bieker M, Slotman BJ, Senan S: Volumetric intensity-modulated arc therapy vs. conventional IMRT in head-and-neck cancer: a comparative planning and dosimetric study. Int J Radiat Oncol Biol Phys 2009, 74:252-259.

24. Doornaert P, Verbakel WF, Bieker M, Slotman BJ, Senan S: RapidArc planning and delivery in patients with locally advanced head-and-neck cancer undergoing chemoradiotherapy. Int J Radiat Oncol Biol Phys 2011, 79:429-435.

25. Gregoire V, Levendag P, Ang KK, Bernier J, Braaksma M, Budach V, Chao C, Coche E, Cooper JS, Cosnard G, Eisbruch A, Emami B, Grau C, Hamoir M, 
Lee N, Maingon P, Muller K, Reychler H: CT-based delineation of lymph node levels and related CTVs in the node-negative neck: DAHANCA, EORTC, GORTEC, NCIC,RTOG consensus guidelines. Radiother Oncol 2003, 69:227-236.

26. Gregoire V, Eisbruch A, Hamoir M, Levendag P: Proposal for the delineation of the nodal CTV in the node-positive and the postoperative neck. Radiother Oncol 2006, 79:15-20.

27. Cox JD, Stetz J, Pajak TF: Toxicity criteria of the Radiation Therapy Oncology Group (RTOG) and the European Organization for Research and Treatment of Cancer (EORTC). Int I Radiat Oncol Biol Phys 1995, 31:1341-1346.

28. Aaronson NK, Ahmedzai S, Bergman B, Bullinger M, Cull A, Duez NJ, Filiberti A, Flechtner H, Fleishman SB, de Haes JC: The European Organization for Research and Treatment of Cancer QLQ-C30: a qualityof-life instrument for use in international clinical trials in oncology. J Nat Cancer Inst 1993, 85:365-376.

29. Bjordal K, hlner-Elmqvist M, Tollesson E, Jensen AB, Razavi D, Maher EJ, Kaasa S: Development of a European Organization for Research and Treatment of Cancer (EORTC) questionnaire module to be used in quality of life assessments in head and neck cancer patients. EORTC Quality of Life Study Group. Acta Oncol 1994, 33:879-885.

30. Kam MK, Leung SF, Zee B, Chau RM, Suen JJ, Mo F, Lai M, Ho R, Cheung KY, Yu BK, Chiu SK, Choi PH, Teo PM, Kwan WH, Chan AT: Prospective randomized study of intensity-modulated radiotherapy on salivary gland function in early-stage nasopharyngeal carcinoma patients. J Clin Oncol 2007, 25:4873-4879.

31. Meirovitz A, Murdoch-Kinch CA, Schipper M, Pan C, Eisbruch A: Grading xerostomia by physicians or by patients after intensity-modulated radiotherapy of head-and-neck cancer. Int I Radiat Oncol Biol Phys 2006, 66:445-453.

32. Wang SL, Zhao ZT, Li J, Zhu XZ, Dong H, Zhang YG: Investigation of the clinical value of total saliva flow rates. Arch Oral Biol 1998, 43:39-43.

33. Parliament MB, Scrimger RA, Anderson SG, Kurien EC, Thompson HK, Field GC, Hanson J: Preservation of oral health-related quality of life and salivary flow rates after inverse-planned intensity-modulated radiotherapy (IMRT) for head-and-neck cancer. Int J Radiat Oncol Biol Phys 2004, 58:663-673.

34. Duprez F, Bonte K, De NW, Boterberg T, De GW, Madani I: Regional relapse after intensity-modulated radiotherapy for head-and-neck cancer. Int J Radiat Oncol Biol Phys 2011, 79:450-458.

35. Saarilahti K, Kouri M, Collan J, Kangasmaki A, Atula T, Joensuu H, Tenhunen M: Sparing of the submandibular glands by intensity modulated radiotherapy in the treatment of head and neck cancer. Radiother Oncol 2006, 78:270-275.

36. Murdoch-Kinch CA, Kim HM, Vineberg KA, Ship JA, Eisbruch A: Dose-effect relationships for the submandibular salivary glands and implications for their sparing by intensity modulated radiotherapy. Int I Radiat Oncol Biol Phys 2008, 72:373-382.

37. Houweling AC, Dijkema T, Roesink JM, Terhaard CH, Raaijmakers CP: Sparing the contralateral submandibular gland in oropharyngeal cancer patients: a planning study. Radiother Oncol 2008, 89:64-70.

38. Saibishkumar EP, Jha N, Scrimger RA, MacKenzie MA, Daly H, Field C, Fallone G, Parliament MB: Sparing the parotid glands and surgically transferred submandibular gland with helical tomotherapy in postoperative radiation of head and neck cancer: a planning study. Radiother Oncol 2007, 85:98-104.

39. Saarilahti K, Kouri M, Collan J, Kangasmaki A, Atula T, Joensuu H, Tenhunen M: Erratum to "Sparing of the submandibular glands by intensity modulated radiotherapy in the treatment of head and neck cancer" [Radiother. Oncol. 78 (2006) 270-275]. Radiother Oncol 2006, 80:107-108.

doi:10.1186/1748-717X-6-74

Cite this article as: Doornaert et al:: Sparing the contralateral submandibular gland without compromising PTV coverage by using volumetric modulated arc therapy. Radiation Oncology 2011 6:74.

\section{Submit your next manuscript to BioMed Central and take full advantage of:}

- Convenient online submission

- Thorough peer review

- No space constraints or color figure charges

- Immediate publication on acceptance

- Inclusion in PubMed, CAS, Scopus and Google Scholar

- Research which is freely available for redistribution

Submit your manuscript at www.biomedcentral.com/submit
C Biomed Central 